\title{
The Relationship Between Perceived Human Resource Management Practices and Turnover-Intention: The Mediating Role of Organizational Attractiveness
}

\author{
Ahmad M. Obeidat ${ }^{1}$ \\ ${ }^{1}$ School of Business, The University of Jordan, Amman, Jordan \\ Correspondence: Ahmad M. Obeidat, School of Business, The University of Jordan, Amman, Jordan. E-mail: \\ a.obeidat@ju.edu.jo
}

Received: Nov. 8, 2018

Accepted: Nov. 28, 2018

Online Published: January 26, 2019

doi:10.5539/mas.v13n2p216

URL: https://doi.org/10.5539/mas.v13n2p216

\begin{abstract}
This study examines whether employees' attraction to the organisation mediates the relationship between their perceptions of human resource management (HRM) practices (as a bundle) and their turnover intentions. Hypotheses were developed based on the propositions of social exchange theory, findings of previous research and theory of reasoned action. Survey data were collected from 297 individuals who work in organisations operating in the Hashemite Kingdom of Jordan. Subsequently, the proposed relations were tested. It was found that: 1) perceived HRM practices is negatively and significantly related to turnover-intention; 2) perceived HRM practices is positively and significantly related to organisational attractiveness; and 3) organisational attractiveness is negatively and significantly related to turnover intention and partially mediates the negative relationship between perceived HRM practices and turnover intention. The implications of these findings for line managers and HR practitioners are also discussed in addition to future research directions.
\end{abstract}

Keywords: human resource management practices, turnover-intention, organisational attractiveness, the hashemite kingdom of Jordan

\section{Introduction}

One of the conclusions that can be drawn from reviewing the extensive literature on the influence of HRM practices on turnover-intentions is that HRM researchers/practitioners have given considerable attention to understanding how they can retain qualified employees. This research attention is not surprising since many researchers (e.g. Vanhala and Ahteela, 2011) recognize that a company's workforce has the potential to be a source of competitive advantage. HRM researchers typically note the following to explain the importance of retaining good employees: the scarcity of highly qualified employees (Story, Castanheira and Hartig, 2016); losing qualified employees can damage competitive advantage due to reductions in quality and productivity (Juhdi, Pa'wan, and Hansaram, 2013); lower employee morale (Ribeiro and Semedo, 2014); and the high costs associated with turnover (e.g. Hemdi and Nasurdin, 2006).

The extant body of research linking HRM practices and turnover-intention (e.g. Ertürk, 2014; Gould-Williams and Mohamed, 2010; Lam, Chen and Takeuchi, 2009) provided empirical evidence confirming that HRM practices plays an important role in maintaining qualified employees by reducing their turnover-intentions. Moreover, many mediators such as: job satisfaction (e.g. Garcia-Chas, Neira-Fontela and Castro-Casal, 2014; Karavardar, 2013; Dhiman and Mohanty, 2010), organisational commitment (e.g. Juhdi et al., 2013), organisational engagement (e.g. Juhdi et al., 2013), affective commitment (e.g. Dhiman and Mohanty, 2010) organisational justice (e.g. Ribeiro and Semedo, 2014), perceived organisational support (e.g. Erturk, 2014), leader-member exchange (e.g. Ertürk, 2014), trust in organisation (e.g. Hemdi and Nasurdin, 2006), job embeddedness (e.g. Bambacas and Kulik, 2013), and organisational citizenship behaviour (e.g. Lam et al., 2009) were proposed by this stream of research in an attempt to reveal the 'black box' between HRM practices and turnover-intentions.

Although this body of research is considerable, one of its limitations is that the range of proposed mediators remains relatively limited and thus, other potential mediators in the relation between HRM practices and turnoverintention are still being left unnoticed. Reviewing the list of proposed mediators in this literature shows that one potential mediator that was overlooked is an employee's attraction to the organisation. Some arguments and 
findings from the recruitment literature highlight this construct's potential as a mediator in the relation between HRM practices and turnover-intention. For example; Story et al., (2016) note that organisational attractiveness is important for attracting and retaining employees. Organisational attractiveness has been found in previous research to be influenced by perceptions of organisational attributes/practices targeting prospective employees (e.g. Lee, Wermer and Kim, 2016; Holtbrugge and Kreppel, 2015; Chhabra and Sharma, 2014) and to influence an individual's intentions/decisions regarding the organisation, namely, the intention to apply to the organisation (e.g. Gomes and Neves, 2011). Another limitation of this literature is that most studies testing the relation between HRM practices and turnover-intention were conducted in western and Far-East countries, while relatively fewer studies were conducted in Jordan, most of which were in the hospitality sector (e.g. Altarawneh and Al-kilani, 2010).

Lastly, an additional notable limitation addressed in this study relates to the examination of organizational attractiveness in the HRM literature. The HRM literature has tended to treat organisational attractiveness as a variable that is mainly relevant to prospective employees (e.g. Story et al., 2016; Ramlugun and Raman, 2015; Backhaus, Stone and Heiner, 2002) rather than to current employees. As a result, its effects on individuals' intentions after they start working for an organisation were mostly untested in the literature.

Using a sample of workers from organizations in Jordan and anchored in the propositions of social exchange theory, theory of reasoned action and findings of previous research, this study aims to address the limitations in these literatures by: 1) proposing and testing the effects of a new mediator (i.e. organizational attractiveness) in the relationship between HRM practices and turnover-intention. 2) Empirically testing the relationship between organizational attractiveness and turnover-intention. And 3) empirically examine the relationships among perceived HRM practices (as a bundle), employees' assessments of organisational attractiveness, and turnoverintention in the context of organizations operating in Jordan.

This paper is structured as follows: first, a theoretical background coupled with a review of literature findings and relevant theory propositions are presented to provide support to the proposed hypotheses; then methods are presented, followed by results. The paper concludes with a discussion of the findings, their implications for managers, and lastly, a discussion of the study limitations and future research directions.

\section{Theory and Hypotheses Development}

\subsection{HRM Practices and Turnover-Intention}

HRM can be described as practices that focus on attracting, hiring, training, motivating and maintaining employees (DeCenzo, Robbins and Verhulst, 2013). Alfes, Shantz and Truss (2012) argue that compared to intended and implemented HRM practices, perceptions of these practices has the most influence over how employees react at work. Moreover, reflecting the current trend in HRM research, Gould-Williams and Mohamed (2010) argued for the effectiveness of viewing and examining HRM practices as a bundle rather than separate practices. Garcia-Chas et al. (2014) note that this bundle of HR practices is important to consider and is known as high-performance or high-commitment or high-involvement work systems. According to Takeuchi, Chen and Lepak (2009) a highperformance work system is pertinent in influencing an employee's behaviour and attitude and it refers to a group of interconnected HRM practices such as: comprehensive recruitment and selection, extensive training and development, incentive pay and performance appraisals. Thus, rather than measuring intended or implemented HRM practice or examining the effects of separate HRM practices, this study is focused on measuring workers' perceptions of high-performance HRM practices as a bundle.

As for turnover-intention, it is defined as a deliberate willingness to leave an organization (Tett and Meyer, 1993). There is considerable empirical evidence in the HRM literature (e.g. Ertürk, 2014; Ribeiro and Semedo, 2014; Baluch, Salge and Piening, 2013; Karavardar, 2013; Bambacas and Kulik, 2013; Juhdi et al., 2013; Alfes et al., 2012; Gould-Williams and Mohamed, 2010; Kuvass and Dysvik, 2010; Dhiman and Mohanty, 2010; Lam et al., 2009; Hemdi and Nasurdin, 2006) that supports the significant negative relationship between perceived HRM practices and turnover-intention. Some of these studies linked specific HRM practices with turnover-intentions. For example; Nawaz and Pangil (2016) examined the effect of perceived human resource development factors (e.g. training and development, career growth, fairness of appraisal) on turnover-intentions and found that salary and performance appraisal fairness had a significant negative relationship with turnover-intention. While other studies linked systems of HRM practices with turnover-intentions. For example: Garcia-Chas et al. (2014) found that perception of high performance work systems had a significant negative effect on engineers' intention to leave. Similarly, Karavardar (2013) found that perceived HRM practices (as a whole) is an essential predictor of turnoverintention.

Basic rationale for this relationship is also provided by the propositions of social exchange theory. Social exchange 
theory (Blua, 1964) posits that within social exchange relationships, receiving a service from another party will generate a felt obligation to reciprocate to this other party. This suggests that within employment relationships between the organisation and employees, when employees perceive that they are receiving beneficial services from the organisation (e.g. HRM practices), they will reciprocate by exhibiting attitudes, intentions and behaviours that are desired by the organisation (e.g. lower turnover-intentions). Based on this discussion, it is expected that the more an employee perceives high-performance HRM practices (as a bundle) to exist, the more likely he/she will lower his/her intention to leave the organisation. Thus, the following hypothesis is proposed:

Hypothesis 1: Perception of HRM practices is significantly and negatively related to turnover-intention.

\subsection{HRM and Organisational Attractiveness}

Within the recruitment literature, organisational attractiveness is defined as seeing the organisation as a desirable entity with which a relationship can be started (Aiman-Smith, Bauer and Cable, 2001). Moreover, it represents an attitude towards an organization (Roque Gomes and Neves, 2010). Lee, Werner and Kim (2016) note that highperformance work systems may serve as perceived organisational attributes and that employers can improve attraction to the organisation by improving working conditions and other HRM aspects (e.g. improving salaries and benefits, providing flexible schedules and career advancement opportunities).

This link between perceived HRM practices (e.g. perceived organizational attributes) and organizational attractiveness (from the viewpoint of job-seekers) was empirically supported by numerous studies in the recruitment literature. Within this stream of research, researchers have found that job seekers' attraction to the organisation is positively affected by specific HRM practices such as: compensation and job security (Holtbrugge and Kreppel, 2015), compensation (Chhabra and Sharma, 2014), managing diversity policy (Williams and Bauer, 1994), paid temporary time-off programs (Altmann and Suess, 2015), pay, advancement, task demands (Lievens and Highhouse, 2003) flexible work schedule namely, telecommuting (Rau and Hyland, 2002) . Other studies within this literature examined the effect of HRM practices as a bundle on organisational attractiveness. For example: Lee et al., (2016) found a significant positive association between high-performance work systems and potential job applicants' attraction to the organisation. Gomes and Neves (2011) found that perceived organisational attributes (i.e. adequate pay, training and development, opportunities to learn, benefits and safety on the job) were positively and significantly related to organisational attractiveness of potential applicants.

However, the number of studies examining the impact of perceived HRM practices on 'current' employees' attraction to the organisation is relatively limited and constrained to certain sectors. Fewer studies exist in this stream of research, for example: Trybou, Gemmel, Vaerenbergh and Annemans (2014) found that professional development opportunities, pay/financial benefits, job security and work-life balance were significantly and positively related to employed physicians' attraction to their employer.

The previous arguments and research findings suggest that perceived HRM practices provide the individual with perceptions about organisational attributes which in turn contributes to this individual's attraction (or lack of) to the organisation.Thus, it is expected that the more an employee perceives HRM practices to be in place, the more likely this employee will be attracted to the organisation. The following hypothesis is proposed:

Hypothesis 2: Perception of HRM practices is significantly and positively related to organisational attractiveness.

\subsection{Organisational Attractiveness and Turnover-Intention}

Research linking current employees' attraction to the organisation and their turnover-intentions is very limited. However, the findings of this research suggest the existence of a negative relation between the two variables. For example, Yurchisin and Park (2010) found that employees' assessment of store image attractiveness positively affected their commitment while this commitment negatively affected their turnover-intention.

Moreover, the recruitment literature provides empirical evidence supporting the positive association between perceived organizational attractiveness and various positive behavioral intentions towards the organization. For example, organizational attractiveness was found to be positively and significantly related to intention to apply to the organisation (e.g. Gomes and Neves, 2011), motivation to pursue employment (e.g. Saks, Leck and Saunders, 1995), and job acceptance intention (e.g. Carless, 2005; Saks et al., 1995). Given this strong empirical evidence showing organizational attractiveness to be positively related to an individual's positive behavioral intentions towards the organization, it is sensible to assume that organizational attractiveness will, at the same time, be negatively related to any negative behavioral intentions (e.g. turnover-intention) towards the organization. In this study, the following proposition is presented and tested: an employee's attraction to the organisation will lead to lowering this employee's turnover-intentions. Thus, the following hypothesis is proposed:

Hypothesis 3: Organisational attractiveness is significantly and negatively related to turnover-intention. 


\subsection{The Mediating Role of Organisational Attractiveness}

As evident by the previous presentation of arguments and research findings, it can be noted that studies (e.g. Ertürk, 2014; Ribeiro and Semedo, 2014) have empirically supported the negative relationship between positive perceptions of HRM practices and turnover-intentions. Furthermore, studies (e.g. Trybou et al., 2014) have shown that perceived HRM practices positively influence an individual's attraction to the organization. Finally, the notion that organizational attractiveness is negatively related to turnover-intentions has been supported and suggested by study findings (e.g. Yurchisin and Park, 2010). Thus, it is sensible to expect that organizational attractiveness will perform a mediating role in the relationship between HRM practices and turnover-intention.

Further support for the proposed mediation model can be provided by the propositions of the 'theory of reasoned action' (Fishbein and Ajzen, 1975). According to Sideridis, Kaissidis and Padeliadu (1998) this theory proposes that behaviour is a result of intention, and intention is a function of attitudes and beliefs. Thus, according to this theory, within an organisational context, employees' beliefs about the organisation's HRM practices will contribute to their attitude towards the organisation (i.e. organisational attractiveness) and this attitude in turn will determine their turnover-intentions. Based on this discussion, the following hypothesis is proposed:

Hypothesis 4: Organisational attractiveness mediates the relationship between perceived HRM practices and turnover-intention.

Figure 1 shows the model and proposed hypotheses that are considered in this study.

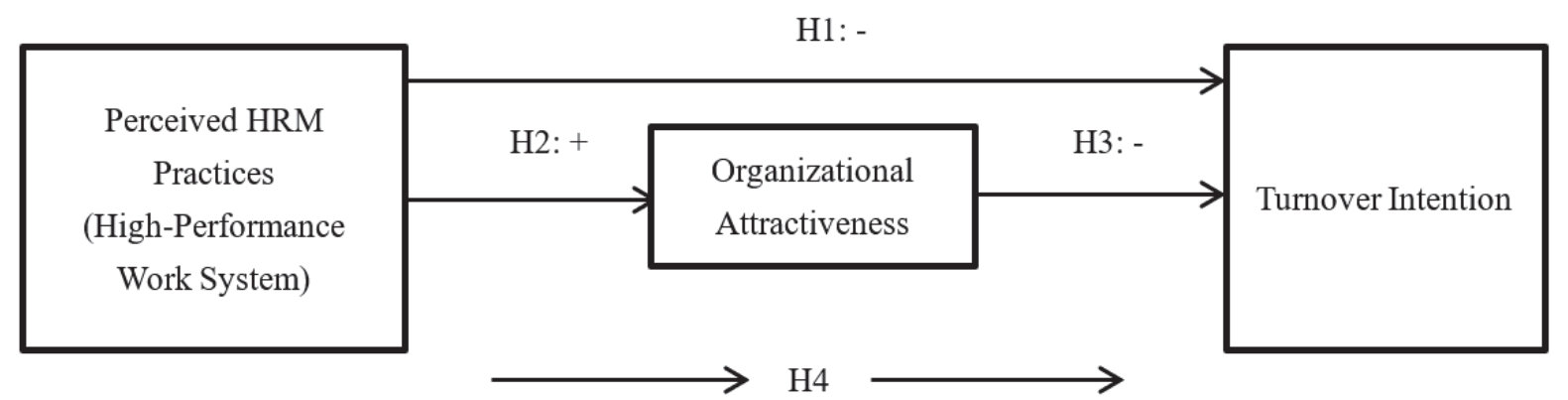

Figure 1. Study model and hypotheses

\section{Methods}

\subsection{Participants and Procedure}

For the purposes of this study, questionnaires were used as the primary data collection method and the study population was identified as employees in managerial and non-managerial jobs within Jordanian workplaces. The questionnaire consisted of two parts, the first included demographic questions while the second included the latent variables' measures. Prior to administering the survey, questionnaire instructions and scale items were translated from English to the Arabic language using a back-translation method. This method was used to make it more likely that most problems in the translation are discovered (Saunders, Lewis and Thornhill, 2009), and thus dealt with accordingly. After being translated, the questionnaire was pilot tested by administering it to 10 working individuals. Consequently, very slight modifications were made since no major issues relating to the questionnaire's wording, content or length were reported.

A snowball sampling method was used for the selection of participants. Questionnaires and envelops were handed to both professional and personal contacts of the researcher for each to administer in his/her respective Jordanian workplace or to any acquaintance working in an organisation located in Jordan. A cover letter was attached to each questionnaire to explain the study objectives and the voluntary nature of participation. The cover letter also assured participants of the anonymity of data they provide and explained that by submitting the questionnaire, the participant gives consent to participate in the study (this was done to avoid collecting any data that can identify the identity of the participant). Additionally, each contact was instructed by the researcher to explain the contents of the cover letter to participants and to instruct them to submit the questionnaire back to the contact in a blank and sealed envelope.

Out of 500 distributed questionnaires, only 307 were returned by participants, reflecting a response rate of $61.4 \%$. 10 returned questionnaires were rejected because they included key parts that were left blank by the participant. Thus, only 297 questionnaires provided usable data and were subsequently used for analysis purposes. 
Of these 297 participants, $57.2 \%$ were male, $53.9 \%$ were married while $41.4 \%$ were divorced, $63.6 \%$ held bachelor degrees while 19.2 held master degrees, $82.2 \%$ were permanent employees, and $67.7 \%$ were in non-managerial jobs. The majority of participants were in the 25-34 age category (49.5\%). Furthermore, participants have mostly income levels either below 499JDs (42.8\%) or between 500-999JDs (37.7\%). The average organisational tenure of participants was approximately 5 years.

\subsection{Measures}

All constructs considered in this study (i.e. perceived HRM practices, organisational attractiveness, and turnoverintention) were measured with multi-item 5-point Likert scales. The response scale for each item ranged from 1 (strongly disagree) to 5 (strongly agree). The measures used were all validated and published in previous research. In very few instances, the wording of a scale item would be slightly modified to better suit the purposes of the study.

- Perceived HRM practices: was measured with a nine-item scale assessing an individual's perception of the following high-performance HRM practices: selection, training and development, performance appraisal, teamwork, job security, pay, communication and involvement. Seven items from the scale (i.e. selection, training and development, teamwork, job security, pay, communication, and involvement) were from the perceived HRM practices scale developed by Gould-Williams and Davis (2005), and two items (i.e. training and performance appraisal) from that developed by Gould-Williams and Mohamed (2010). The items of the scale were developed and used in previous studies (i.e. Gould-Williams, 2003; Gould-Williams and Davis, 2005; Gould-Williams and Mohamed, 2010) and according to Alfes et al. (2012) these measures have high validity and reliability and items are suitable for workers from different occupations. Sample items include: "A rigorous selection process is used to select new recruits" and "I feel fairly rewarded for the amount of effort I put into my job". Responses to the scale's items were averaged to compute a score of each participant's perception of high-performance HR practices.

- Organisational attractiveness: was measured with a five-item scale assessing the organisation's 'general attractiveness' proposed and validated by Highhouse, Lievens and Sinar (2003). The wording of the scale's items was slightly modified to suit the nature of participants (i.e. current employees rather than prospective employees). Sample items include: "For me, my company is a good place to work" and "Having a job at my company is very appealing to me". Highhouse et al. (2003) reported a Cronbach alpha score for this scale equaling 88 .

- Turnover-intention: was measured using a three-item scale developed by Chang, Wang and Huang (2013). Sample items include: "I often think of leaving the organisation" and "If I may choose again, I will choose to work for another organisation". Chang et al. (2013) reported a Cronbach alpha of .85 for this scale.

- Control variables: previous research (e.g. Kuvass and Dysvik, 2010; Dhiman and Mohanty, 2010) show that age and education level are significantly associated with turnover-intentions. However, in the present study only age $(1=>18,2=18-24,3=25-34,4=35-44,5=45=54,6=55$ and above $)$ was controlled for in the regression analyses since the relationship between education level and turnover-intention was not statistically significant (see Table 1).

\section{Results}

\subsection{Preliminary Analyses and Measurement Validation}

Given that all variables in this study were measured using a single source, it was necessary to check if common method variance was present in this study. To that end, the Harman's one-factor test (see Podsakoff and Organ, 1986) was conducted (using IBM SPSS statistics 23) on all scale items used in the study. Results of the factor analysis (unrotated solution) showed that multiple factors emerged in the analysis and that the first factor emerging accounted for less than $50 \%$ of the variance, thus indicating that common method bias was not a major concern in this study.

Next, using Amos 22, a confirmatory factor analysis (CFA) was conducted to assess model fit. The measurement model tested included the following variables: perceived HRM practices, organisational attractiveness and turnover-intention. The chi-square/degrees of freedom ratio (X2/df) was less than the cut-off threshold of 3 (Hu and Bentler, 1999). The root mean square error of approximation (RMSEA) was within the moderate range of .05 - .010 (Hu and Bentler, 1999). Finally the comparative fit index (CFI) and Goodness of fit index (GFI) were both above the traditional cut-off value of .90 (Hu and Bentler, 1999). Thus, the analysis provided evidence of a good and reasonable model fit to the data $(\mathrm{GFI}=.907 ; \mathrm{CFI}=.954 ; \mathrm{RMSEA}=0.065 ; \mathrm{X} 2=251.016, \mathrm{df}=111, \mathrm{p}<0.001$; and $\mathrm{X} 2 / \mathrm{df}=2.261$ ). 
Table 1 presents the means, standard deviations, correlations and reliabilities of the variables examined in this study (analysis was conducted using IBM SPSS statistics 23). The reliability scores (shown in Table 1 in the diagonal and in parentheses) for all measures used in this study (i.e. perceived HRM practices, organisational attractiveness and turnover-intention) exceeded the acceptable level of .7 (Pallant, 2010) and suggested very good to excellent internal consistency. Furthermore, the Cronbach Alpha for perceived HRM practices was .913, thus, indicating that participants viewed HRM practices as a bundle.

In relation to correlation analysis results, Table 1 show that perceived HRM practices are positively and significantly related to organisational attractiveness $\left(r=.691^{* *}, \mathrm{p}<.01\right)$ and negatively and significantly related to turnover-intention $\left(\mathrm{r}=-.593^{* *}, \mathrm{p}<.01\right)$. Organisational attractiveness was also found to be negatively and significantly related to turnover-intention $\left(\mathrm{r}=-.614^{* *}, \mathrm{p}<.01\right)$. Results also show that of the control variables, only age $(\mathrm{r}=-.116, \mathrm{p}<.05)$ was significantly related to turnover-intention. These results provide initial support to $\mathrm{H} 1$, $\mathrm{H} 2$, and $\mathrm{H} 3$ (Figure 1).

Table1. Means, standard deviations, correlations, and reliabilities.

\begin{tabular}{|c|c|c|c|c|c|c|c|}
\hline Variables & $\mathrm{M}$ & SD & 1 & 2 & 3 & 4 & 5 \\
\hline 1. Age (categorical) & 3.138 & .98869 & - & & & & \\
\hline 2. Education level (categorical) & 2.340 & .89415 & $.138^{*}$ & - & & & \\
\hline 3. Perceived HRM practices & 3.204 & .85068 & -.008 & .026 & $(.913)$ & & \\
\hline 4. Organisational attractiveness & 3.639 & .80393 & .082 & -.017 & $.691 * *$ & $(.841)$ & \\
\hline 5. Turnover-intention & 2.728 & 1.0326 & $-.116^{*}$ & .074 & $-.593 * *$ & $-.614 * *$ & $(.845)$ \\
\hline
\end{tabular}

Notes. $N=297 .{ }^{*} p<.05,{ }^{*} p<.01$. Reliabilities are shown in parentheses. Age: $1=$ below $18,2=18-24,3=$ $25-34,4=35-44,5=45-54,6=55$ and above. Educational level: $1=$ high school, $2=$ bachelor degree, $3=$ master degree, $4=\mathrm{PhD}$ degree.

\subsection{Hypotheses Testing}

Separate hierarchical multiple regression analyses were conducted (Using IBM SPSS statistics 23) to test the hypothesized relationships in this study. To test the mediation model, the three-step (conditions) mediation test proposed by Baron and Kenny (1986) was followed. First, the independent variable, 'perceived HRM practices', must be significantly related to the outcome/dependent variable, 'turnover-intention' (Hypothesis 1); second, the independent variable, 'perceived HRM practices', must be significantly related to the mediator variable, 'organisational attractiveness' (Hypothesis 2); and finally, the mediating variable, 'organisational attractiveness', must be significantly related to the dependent variable, 'turnover-intention', while controlling for the independent variable, perceived HRM practices.

As Ertürk (2007) puts it, for mediation to exist, the significant relation between the independent and the dependent variable must either disappear or be reduced when the mediator is included in the regression equation. Furthermore, according to Lam et al., (2009) in the third step, the unstandardized beta weight of the independent variable becoming not-significant indicates full mediation, while still-significant unstandardized beta weight for the independent variable indicates partial mediation.

Table 2. Hierarchical regression analyses examining the hypothesized relationship

\begin{tabular}{|c|c|c|c|}
\hline \multirow{8}{*}{ Variable entered } & Model 1 & Model 2 & Model 3 \\
\hline & & & Relation between \\
\hline & Relation between & Relation between & organisational \\
\hline & perceived HRM & perceived HRM & attractiveness and \\
\hline & practices and & practices and & turnover-intention \\
\hline & turnover-intention & organisational & (H3) while controlling \\
\hline & (H1) & attractiveness (H2) & $\begin{array}{c}\text { for the independent } \\
\text { variable }(\boldsymbol{H} 4)\end{array}$ \\
\hline & $\begin{array}{c}\text { Standardized } \beta \\
(\text { unstandardized } \beta)^{a}\end{array}$ & $\begin{array}{c}\text { Standardized } \beta \\
(\text { unstandardized } \beta)^{a}\end{array}$ & $\begin{array}{c}\text { Standardized } \beta \\
(\text { unstandardized } \beta)^{a}\end{array}$ \\
\hline
\end{tabular}




\begin{tabular}{|c|c|c|c|}
\hline \multicolumn{4}{|l|}{ Control variables } \\
\hline Age & $-.121 * *(-.127 * *)$ & $b$ & $-.088 *(-.092 *)$ \\
\hline$R^{2}\left(\right.$ Adjusted $\left.R^{2}\right)$ & $.014 *(.010 *)$ & $b$ & $.014 *(.010 *)$ \\
\hline \multicolumn{4}{|l|}{ Independent variable } \\
\hline Perceived HRM practices & $-.594 * * *(-.721 * * *)$ & $.691 * * *(.653 * * *)$ & $-.334 * * *(-.405 * * *)$ \\
\hline$\Delta R^{2}$ & $.353^{* * *}$ & $.478^{* * *}$ & $.353^{* * *}$ \\
\hline Total $R^{2}$ (Adjusted $\left.R^{2}\right)$ & $.366^{* * *}(.362 * * *)$ & $.478 * * *\left(.476^{* * *}\right)$ & $.366^{* * *}(.362 * * *)$ \\
\hline \multicolumn{4}{|l|}{ Mediator variable } \\
\hline Organisation attractiveness & & & $-.376 * * *(-.483 * * *)$ \\
\hline$\Delta R^{2}$ & & & $.073^{* * *}$ \\
\hline Total $R^{2}\left(\right.$ Adjusted $\left.R^{2}\right)$ & & & $.439 * * *(.433 * * *)$ \\
\hline
\end{tabular}

Notes. $N=297 .{ }^{*} p<.05,{ }^{* *} p<.01, * * * p<.001 .{ }^{a}$ standardized and unstandardized $\beta$ values are taken from the final model in each regression analysis. ${ }^{b}$ age was not significantly correlated with organisational attractiveness, thus it was not controlled for in the regression equation in model 2.

As shown in Table 2 (under the column labeled 'model 1') and in relation to H1, perceived HRM practices (Standardized $\beta=-.594^{* * *}$, unstandardized $\beta=-.721^{* * *}, \mathrm{p}<.001$ ) is shown to be negatively and significantly related to turnover-intentions and individually explaining $35.3 \%$ of the variance in the dependent variable $(\mathrm{F}=$ 84.991, $\mathrm{p}=.000$ ). This result fulfills the first condition (see Baron and Kenny, 1986) for mediation and provides support to Hypothesis 1. In relation to H2 and under the column labeled 'model 2' (Table 2), results of the regression analysis show that perceived HRM practices (Standardized $\beta=.691^{* * *}$, unstandardized $\beta=.653^{* * *}, p$ $<.001$ ) is positively and significantly related to the mediator, explaining $47.8 \%$ of the variance in organisational attractiveness $(\mathrm{F}=270.033, \mathrm{p}=.000)$. This result fulfills the second condition for mediation and provides support to $\mathrm{H} 2$.

Finally, under the column labeled 'model 3', results of hierarchical regression analysis show that the mediator 'organisational attractiveness' (Standardized $\beta=-.376^{* * *}$, unstandardized $\beta=-.483^{* * *}, \mathrm{p}<.001$ ) is negatively and significantly related to turnover-intentions (controlling for age and perceived HRM practices), individually explaining $7.3 \%$ of the variance in the dependent variable $(\mathrm{F}=76.496, \mathrm{p}=.000)$, thus, supporting $\mathrm{H} 3$, while the effect size (Standardized and unstandardized $\beta$ weights) of perceived HRM practices (Standardized $\beta=-.334 * * *$, unstandardized $\beta=-.405^{* * *}, \mathrm{p}<.001$ ) became lower (compared to weights reported in column labeled 'model $1^{\prime} /$ Table 2) yet still significant.

These results fulfill the third condition for mediation and provide support to H4. However, the latter result indicates that organisational attractiveness partially mediates (rather than fully mediates) the relationship between perceived HRM practices and turnover-intention.

\section{Discussion}

This study attempted to examine how perceived HRM practices influence employees' turnover-intentions through the mediating effects of employees' attraction to the organisation. As noted earlier, despite its evident potential as a mediator, organisational attractiveness has not received much consideration when developing mediation models linking HRM practices to turnover-intention or other individual and organisational outcomes. This study, unlike the majority of previous research examining organisational attractiveness, has examined this construct from the view point of current employees rather than potential employees. Thus, a mediation model was proposed with organisational attractiveness as a mediator. The mediation model was developed based on the propositions of social exchange theory and the theory of reasoned action in addition to findings of previous research. The research model and hypotheses were tested using data collected from a sample of individuals (i.e. employees and managers; $\mathrm{N}=297$ ) working for organisations located in Jordan.

The results of this study provided empirical support to all proposed hypotheses, thus, all hypotheses were accepted. This study found that perceived HRM practices were significantly and negatively related to turnover-intentions. This result is consistent with findings of previous research (e.g. Garcia-Chas et al., 2014; Ribeiro and Semedo, 2014; Karavardar, 2013; Gould-Williams and Mohamed, 2010) and thus, further confirms the important role HRM practices play in maintaining an organisation's employees while adding to the diversity of national contexts in 
which similar results were reported. Consistent with findings of previous research (e.g. Trybou et al., 2014) the second finding of this study was the significant and positive relationship between perceived HRM practices and organizational attractiveness. This finding supports the argument that high performance HRM practices serve as organisational attributes influencing an employee's attraction to the organization (Lee et al., 2016). Furthermore, this finding is in alignment with the notion that employee' interpretations of HR practices in terms of how much the organisation values employees will generate positive employee attitudes (Garcia-Chas et al., 2014). This finding provides further confirmation of the importance of high-performance HRM practices in developing employee's attraction to the employer. Collectively, the first two findings provide additional empirical support to the argument that high performance HR systems are important in influencing an employee's attitudes (Takeuchi et al., 2009).

The third finding of this study was the negative and significant relationship between organisational attractiveness and an employee's turnover-intention. This finding aligns with and contributes to the sparse literature (e.g. Yurchisin and Park, 2010) linking orgnisational attractiveness and turnover-intention. This finding suggests that organisational attractiveness plays a role in limiting and reducing an employee's intentions to leave the organisation.

Lastly, it was found that organisational attractiveness partially mediates the significant negative relationship between perceived HRM practices and turnover-intention. This supports the notion that the effects of HRM practices on turnover-intention might not be simple (Lam et al's., 2009), thus, highlighting the need for further examination of mediators in the relationship between HRM practices and turnover-intention. One explanation for the partial mediation might be that most psychological/social research deal with phenomena that have multiple causes, thus it would be more realistic to expect mediators that reduce (rather than eliminate) the relationship between the independent and dependent variables (Baron and Kenny, 1986). Nevertheless, this finding suggests that organisational attractiveness plays a role in explaining how HRM practices influence turnover-intentions.

\subsection{Theoretical Implications}

This study provides a number of contributions to the extant literature. First, this study contributes another potential mediator that has not been considered before in the literature focusing on how HRM practices influence turnoverintention. Thus, it extends the range of mediators examined in the relation between HRM practices and turnoverintentions and it adds an additional and new insight on how organisations can lower the turnover-intentions of their valued employees. Second, the study also adds to the increasing empirical evidence supporting the relationship between HRM practices and turnover-intention and provides an additional test of the relationship in the context of organizations in Jordan. Thus, adding to the diversity of contexts in which the relationship was empirically tested. Finally, this study contributes to the turnover-intention literature by providing empirical evidence of the direct influence of organizational attractiveness (a construct that seems to have been rarely examined within the context of an existing employment relationship) on turnover-intentions.

\subsection{Practical Implications}

The findings of this study suggest that perceptions of HRM practices and an employee's attraction to her/his organisation play significant roles in reducing an employee's turnover-intention. Thus, to maintain their qualified workforce, organisations (represented by managers and HR practitioners) should focus on two aspects: first, managing and enhancing employees' perceptions of HRM practices, that is, ensure that employees perceive the organisation's HRM practices positively, and second, managing and promoting the employees' attraction to the organisation.

Organisations can take into consideration a number of possible courses of action for managing these two aspects. First, in relation to enhancing employees' perceptions of high-performance HRM practices, organisations can increase the time, effort and financial capital they invest in planning, and implementing high performance HRM practices. Training courses on the nature of high-performance HRM practices and how to implement them in the organisation or work unit can be offered to line and/or HR managers. Furthermore, investing time, effort and financial capital in the communication of these practices with employees is paramount since according to GarciaChas et al., (2014), for employees to be aware of these practices, it is important to communicate with them about these practices.

Second, in relation to managing and promoting the organisation's attractiveness and based on the second finding of this study (i.e. the significant positive relation between perceived HRM practices and attraction to the organisation), organisations can focus, as noted and discussed earlier, on enhancing employees' perceptions of high-performance HRM system. Another possible course of action for organisations would be to periodically assess employees' levels of attraction to the organisation, then collect feedback from these employees as to what 
makes them attracted or less attracted to the organisation, and subsequently work on improving those areas that would enhance the employees' attraction to the organisation.

\subsection{Limitations and Future Research}

The study findings should be viewed while taking into consideration the limitations of this study. One of the limitations of this study is the possibility of common method bias given that all variables of interest were assessed by the same source. Even though the Harman's one factor test conducted indicated that common method bias was not a major issue in this study, none the less, future research should attempt to apply procedural remedies suggested by the literature to control and reduce common method bias. One possible remedy proposed by Podsakoff, Mackenzie, lee and Podsakoff (2003) would be to separate the measurement of the independent variable from that of the dependent variable by introducing a time lag between the assessments of the two variables or use for each scale a different response format. Another limitation is the cross sectional design of this study which makes it difficult to infer causal relationships among the variables. Thus, future research on this topic can use longitudinal designs to infer causality more accurately.

In relation to possible future research directions, other mediators may play a role in explaining the influence of perceived HRM practices on turnover-intentions. Thus, future research should continue examining these mediators and suggest new ones. Another future research possibility would be to duplicate the current study in a different national/cultural context to provide evidence that contributes to the generalizability of the study findings to different national contexts. Future research can also examine the mediating role of organisational attractiveness on the relationship between HRM practices and other outcome variables (both attitudinal and behavioural) such as: motivation, loyalty, commitment, individual performance, organisational performance, and organisational or interpersonal citizenship behaviours. Lastly, given that this study has assessed perceived HRM practices as a bundle; future research can further explore the relationship between perceived HRM practices and organisational attractiveness by examining the relative importance of individual HRM practices (e.g. recruitment procedures, selection procedures, performance management practices, compensation management practices, training and development, etc) in explaining variations in an employee's attraction to the organisation.

\section{References}

Aiman-Smith, L., Bauer, T. N., \& Cable, D. M. (2001). Are you attracted? Do you intend to pursue? A recruiting policy-capturing study. Journal of Business and Psychology, 16(2), 219-237. https://doi.org/10.1023/A:1011157116322

Alfes, K., Shantz, A., \& Truss, C. (2012). The link between perceived HRM practices, performance and well-being: The moderating effect of trust in the employer. Human Resource Management Journal, 22(4), 409-427. https://doi.org/10.1111/1748-8583.12005

Altarawneh, I., \& Al-Kilani, M. H. (2010). Human resource management and turnover intentions in the Jordanian hotel sector. Research and Practice in Human Resource Management, 18(1), 46-59.

Altmann, S., \& Suess, S. (2015). The influence of temporary time offs from work on employer attractiveness-An experimental study. Management Revue, 26(4), 282-305. https://doi.org/10.5771/0935-9915-2015-4-282

Backhaus, K. B., Stone, B. A., \& Heiner, K. (2002). Exploring the relationship between corporate social performance and employer attractiveness. Business \& Society, 41(3), 292-318. https://doi.org/10.1177/0007650302041003003

Baluch, A. M., Salge, T. O., \& Piening, E. P. (2013). Untangling the relationship between HRM and hospital performance: The mediating role of attitudinal and behavioural HR outcomes. The International Journal of Human Resource Management, 24(16), 3038-3061. https://doi.org/10.1080/09585192.2013.775027

Bambacas, M., \& Kulik, T. C. (2013). Job embeddedness in China: How HR practices impact turnover intentions. The International Journal of Human Resource Management, 24(10), 1933-1952. https://doi.org/10.1080/09585192.2012.725074

Baron, R. M., \& Kenny, D. A. (1986). The moderator-mediator variable distinction in social psychological research: Conceptual, strategic, and statistical considerations. Journal of Personality and Social Psychology, 51(6), 1173-1182.

Blau, P, M. (1964). Exchange and Power in Social Life. New York: John Wiley \& Sons, Inc.

Carless, S. A. (2005). Person-job fit versus person-organization fit as predictors of organizational attraction and job acceptance intentions: A longitudinal study. Journal of Occupational and Organizational Psychology, 78(3), 411-429. https://doi.org/10.1348/096317905X25995 
Chang, W. J. A., Wang, Y. S., \& Huang, T. C. (2013). Work design-related antecedents of turnover intention: A multilevel approach. Human Resource Management, 52(1), 1-26. https://doi.org/10.1002/hrm.21515

DeCenzo, D. A., Robbins, S. P., \& Verhulst, S. L. (2013). Human resource management. Hoboken Wiley.

Dhiman, G. R., \& Mohanty, R. P. (2010). HRM practices, attitudinal outcomes and turnover intent: An empirical study in Indian oil and gas exploration and production sector. South Asian Journal of Management, 17(4), 74104.

Ertürk, A. (2007). Increasing organizational citizenship behaviors of Turkish academicians: Mediating role of trust in supervisor on the relationship between organizational justice and citizenship behaviors. Journal of Managerial Psychology, 22(3), 257-270. https://doi.org/10.1108/02683940710733089

Ertürk, A. (2014). Influences of HR practices, social exchange, and trust on turnover intentions of public IT professionals. Public Personnel Management, 43(1), 140-175. https://doi.org/10.1177/0091026013517875

Fishbein, M. and Ajzen, I. (1975). Belief, attitude, intention and behaviour: An introduction to theory and research. Reading, MA: Addison-Wesley.

García-Chas, R., Neira-Fontela, E., \& Castro-Casal, C. (2014). High-performance work system and intention to leave: a mediation model. The International Journal of Human Resource Management, 25(3), 367-389. https://doi.org/10.1080/09585192.2013.789441

Gomes, D., \& Neves, J. (2011). Organizational attractiveness and prospective applicants' intentions to apply. Personnel Review, 40(6), 684-699. https://doi.org/10.1108/00483481111169634

Gould-Williams, J. (2003). The importance of HR practices and workplace trust in achieving superior performance: a study of public-sector organizations. International Journal of Human Resource Management, 14(1), 28-54. https://doi.org/10.1080/09585190210158501

Gould-Williams, J., \& Davies, F. (2005). Using social exchange theory to predict the effects of HRM practice on employee outcomes: An analysis of public sector workers. Public management review, 7(1), 1-24. https://doi.org/10.1080/1471903042000339392

Gould-Williams, J., \& Mohamed, R. B. (2010). A comparative study of the effects of 'best practice' HRM on worker outcomes in Malaysia and England local government. The International Journal of Human Resource Management, 21(5), 653-675. https://doi.org/10.1080/09585191003658821

Hemdi, M. A., \& Nasurdin, A. M. (2006). Predicting turnover intentions of hotel employees: The influence of employee development human resource management practices and trust in organization. Gadjah Mada International Journal of Business, 8(1), 21-42. https://doi.org/10.22146/gamaijb.5625

Highhouse, S., Lievens, F., \& Sinar, E. F. (2003). Measuring attraction to organizations. Educational and Psychological Measurement, 63(6), 986-1001. https://doi.org/10.1177/0013164403258403

Holtbrügge, D., \& Kreppel, H. (2015). Employer attractiveness of Chinese, Indian and Russian firms in Germany: Signaling effects of HR practices. Corporate Reputation Review, 18(3), 223-242. https://doi.org/10.1057/crr.2015.12

Hu, L. T., \& Bentler, P. M. (1999). Cutoff criteria for fit indexes in covariance structure analysis: Conventional criteria versus new alternatives. Structural Equation Modeling: A Multidisciplinary Journal, 6(1), 1-55. https://doi.org/10.1080/10705519909540118

Juhdi, N., Pa'wan, F., \& Hansaram, R. M. K. (2013). HR practices and turnover intention: the mediating roles of organizational commitment and organizational engagement in a selected region in Malaysia. The International Journal of Human Resource Management, 24(15), 3002-3019. https://doi.org/10.1080/09585192.2013.763841

Karavardar, G. (2013). Determining the mediating effect of job satisfaction on turnover intention: A study in the hazelnut industry of Giresun. Journal of Academic Research in Economics, 5(3), 376-396.

Kuvaas, B., \& Dysvik, A. (2010). Does best practice HRM only work for intrinsically motivated employees? The International Journal of Human Resource Management, 21(13), 2339-2357. https://doi.org/10.1080/09585192.2010.516589

Lam, W., Chen, Z., \& Takeuchi, N. (2009). Perceived human resource management practices and intention to leave of employees: the mediating role of organizational citizenship behaviour in a Sino-Japanese joint venture. The International Journal of Human Resource Management, 20(11), 2250-2270. 
https://doi.org/10.1080/09585190903239641

Lee, H., Werner, S., \& Kim, T. Y. (2016). High performance work systems and organization attraction: The moderating effects of vocational interests. Employee Relations, 38(5), 682-702. https://doi.org/10.1108/ER08-2015-0165

Leekha Chhabra, N., \& Sharma, S. (2014). Employer branding: strategy for improving employer attractiveness. International Journal of Organizational Analysis, 22(1), 48-60. https://doi.org/10.1108/IJOA-09-2011-0513

Lievens, F., \& Highhouse, S. (2003). The relation of instrumental and symbolic attributes to a company's attractiveness as an employer. Personnel Psychology, 56(1), 75-102. https://doi.org/10.1111/j.17446570.2003.tb00144.x

Nawaz, M. S., \& Pangil, F. (2016). The effect of fairness of performance appraisal and career growth on turnover intention. Pakistan Journal of Commerce and Social Sciences, 10(1), 27-44.

Pallant, J. (2010). SPSS survival manual: A step by step guide to data analysis using SPSS. Berkshire: McGrawHill.

Podsakoff, P. M., \& Organ, D. W. (1986). Self-reports in organizational research: Problems and prospects. Journal of Management, 12(4), 531-544. https://doi.org/10.1177/014920638601200408

Podsakoff, P. M., MacKenzie, S. B., Lee, J. Y., \& Podsakoff, N. P. (2003). Common method biases in behavioral research: A critical review of the literature and recommended remedies. Journal of Applied Psychology, 88(5), 879-903. https://doi.org/10.1037/0021-9010.88.5.879

Ramlugun, V. G., \& Raman, M. T. S. (2015). How do job seekers respond to organizational attractiveness? A study based on CSR dimensions. International Journal of Arts and Sciences, 8(5), 379-392.

Rau, B. L., \& Hyland, M. A. M. (2002). Role conflict and flexible work arrangements: The effects on applicant attraction. Personnel Psychology, 55(1), 111-136. https://doi.org/10.1111/j.1744-6570.2002.tb00105.x

Ribeiro, N., \& Semedo, A. S. (2014). Human resources management practices and turnover intentions: The mediating role of organizational justice. IUP Journal of Organizational Behavior, 13(1), 7-32.

Roque Gomes, D., \& Neves, J. (2010). Employer branding constrains applicants' job seeking behaviour?. Revista de Psicología del Trabajo y de las Organizaciones, 26(3), 223-234. https://doi.org/10.5093/tr2010v26n3a6

Saks, A. M., Leck, J. D., \& Saunders, D. M. (1995). Effects of application blanks and employment equity on applicant reactions and job pursuit intentions. Journal of Organizational Behavior, 16(5), 415-430. https://doi.org/10.1002/job.4030160504

Saunders, M. Lewis, P. \& Thornhil, A. (2009). Research Methods for Business Students. Harlow: Prentice Hall.

Sideridis, G. D., Kaissidis, A., \& Padeliadu, S. (1998). Comparison of the theories of reasoned action and planned behaviour. British Journal of Educational Psychology, 68(4), 563-580. https://doi.org/10.1111/j.20448279.1998.tb01312.x

Story, J., Castanheira, F., \& Hartig, S. (2016). Corporate social responsibility and organizational attractiveness: implications for talent management. Social Responsibility Journal, 12(3), 484-505. https://doi.org/10.1108/SRJ-07-2015-0095

Takeuchi, R., Chen, G., \& Lepak, D. P. (2009). Through the looking glass of a social system: cross-level effects of high-performance work systems on employees' attitudes. Personnel Psychology, 62(1), 1-29. https://doi.org/10.1111/j.1744-6570.2008.01127.x

Tett, R. P., \& Meyer, J. P. (1993). Job satisfaction, organizational commitment, turnover intention, and turnover: path analyses based on meta-analytic findings. Personnel Psychology, 46(2), 259-293. https://doi.org/10.1111/j.1744-6570.1993.tb00874.x

Trybou, J., Gemmel, P., Van Vaerenbergh, Y., \& Annemans, L. (2014). Hospital-physician relations: the relative importance of economic, relational and professional attributes to organizational attractiveness. BMC Health Services Research, 14(1), 232-240. https://doi.org/10.1186/1472-6963-14-232

Vanhala, M., \& Ahteela, R. (2011). The effect of HRM practices on impersonal organizational trust. Management Research Review, 34(8), 869-888. https://doi.org/10.1108/01409171111152493

Williams, M. L., \& Bauer, T. N. (1994). The effect of a managing diversity policy on organizational attractiveness. Group \& Organization Management, 19(3), 295-308. https://doi.org/10.1177/1059601194193005 
Yurchisin, J., \& Park, J. (2010). Effects of retail store image attractiveness and self-evaluated job performance on employee retention. Journal of Business and Psychology, 25(3), 441-450. https://doi.org/10.1007/s10869010-9161-x

\section{Copyrights}

Copyright for this article is retained by the author(s), with first publication rights granted to the journal.

This is an open-access article distributed under the terms and conditions of the Creative Commons Attribution license (http://creativecommons.org/licenses/by/4.0/). 